\title{
Ethical Dilemmas in Geosciences. We Can Ask, but, Can We Answer?
}

\author{
EDUARDO MARONE \\ CEM/UFPR, IOI-TC-LAC, Brazil \\ IAPG - International Association for Promoting Geoethics \\ edmarone@gmail.com \\ SILVIA PEPPOLONI \\ Istituto Nazionale di Geofisica e Vulcanologia \\ IAPG - International Association for Promoting Geoethics \\ silvia.peppoloni@ingv.it
}

\begin{abstract}
The choices of a geoscientist while carrying out his/her activity are always accompanied by ethical implications, because they can have a strong impact on the population, the natural environment, the economy, the landscape and the cultural resources of the affected area. It is not uncommon for a geoscientist to be faced with ethical dilemmas that are problems with a difficult solution, since options to solve such dilemmas will have negative consequences. How does one make a choice in these circumstances? What is the ethical duty of geoscientists and what has to be their professional attitude? In which cases do they have the duty to take action or the duty to not act (duty of omission)? A brief review of the concepts formulated by philosophers in reference to ethics can serve to provide some answers to the above questions and to understand how geoscientists can best serve society.
\end{abstract}

\begin{abstract}
"Among men there are but few who behave according to principles - which is extremely good, as it can so easily happen that one errs in these principles, and then the resulting disadvantage extends all the further, the more universal the principle and the more resolute the person who has set it before himself." (Immanuel Kant, 1764)
\end{abstract}

\section{INTRODUCTION}

$\mathrm{E}$ thics is a branch of philosophy (moral philosophy) having as many definitions as there are philosophers. One might consider it as the main philosophical "tool" to identify right and wrong conduct (Fieser, 2017) and to define which are our ethical duties and obligations, once we have established a shared set of reference values.
One of the critical situations we face, as humans in general and as geoscientists in particular, occurs when we are exposed to an ethical dilemma. An ethical dilemma is a problem of difficult solution, which offers an alternative between two or more options, none of which is fully acceptable in practice or both with negative consequences.

Dilemmas arise because of conflicts between right or wrong for the actions/means and the bad or good of the consequences/ends. They involve a conflict between ethical duties, in which to follow one would result in violating another.

Moral Philosophy tries to provide rules and principles enabling us trying to solve ethical dilemmas. Among the many, one of the best known ethical guides is the "Golden Rule", or law of reciprocity, a principle suggesting treat- 
ing the others as one would wish to be treated (Flew, 1979).

One alleged goal of ethics would be to help us in determining how to solve ethical dilemmas. Firstly, we should question:

- Is it possible to solve such dilemmas?

- What must we do if we cannot?

It is not always easy or possible to apply the Golden Rule or other ethical laws to solve a given dilemma.

In geosciences, when faced with a (geo)ethical dilemma, geoscientists have to initially answer some questions:

- Can we solve any of the dilemmas that appear in the practice of our profession?

- Always?

- In some cases?

- Not at all?

- What if we cannot?

- Must we?

In the following, we try to analyse if it is possible to answer the above questions and, if not, what should be the ethical duty of a geoscientist when facing an apparently unsolvable dilemma.

\section{PROBLEMS, QUESTIONS AND GEOETHICAL DILEMMAS}

Ethical behaviour is primarily about making correct choices. Thus, we have to keep in mind that, when confronting professional dilemmas, we have to deal with ethical consequences of our work (Bobrowsky et al., 2017). Ethics is intimately tied to critical thinking, pushing us to use our best "shelter" of logical/scientific tools / methods to solve problems that have ethical implications. But that is not enough.

In fact, dilemmas are particular problems that create situations that could put us on difficult grounds, forcing us to decide based on what we think the ethically correct course of action would be. Ethical dilemmas, however, need decisions using critical thinking, on what would be a logical/rational way of action. Nonetheless, there are no truly 'right' solution to such dilemmas, as they often ask us to com- pare two different ethical or logical imperatives and choose which one we feel is the most important (Wall, 2003).

Dilemmas arise when we do not have a solution satisfying both ethical and logical premises, although many modern philosophers propose theories to resolve such situations. In fact, if a dilemma has a solution that does not violate logical thinking nor ethical principles, it is not a real dilemma. However, we should consider also that dilemmas are solvable using scientific means but may violate ethical principles. For example, the opening of a mine in an economically depressed area could have indisputable benefits for the local population, as this activity would provide new jobs, improve the facilities and infrastructure of the territory, increase community services and foster local microeconomics. Nevertheless, at the same time, the mine may have a strong impact on the natural environment, disrupt ecosystems, lead to landscape deterioration, become a source of groundwater pollution, or trigger new hazards in the area.

Therefore, there are positive and negative aspects to be considered, according to different perspectives: in the short and long term, at both small and large scales.

In the short term, the mine can represent a great economic benefit for the local population but, in the long term, it may impoverish the area and its inhabitants from an environmental and aesthetic point of view, by overturning the initial positive effects.

Considering the local scale, the mine may have negative repercussions on the quality of the environment, whereas in a large-scale perspective it can have positive effects on the country's GDP.

How long (in terms of time and space) will those effects (positive and negative) persist?

Hence, a specific situation, not necessarily a dilemma as in the short term, could become a dilemma in the long term. Although we all want dilemmas solved, such a perception however, may be hopeless if it turns out that the nature of dilemmas is to remain dilemmas (Grassian, 1992). This does not mean we cannot find an acceptable solution from a scientific/technical point of view. 
If we focus on geoethical dilemmas, taking into account the challenging question of the philosopher Immanuel Kant (formulated in 1764):

- Is it rational for me to will that my choice become a universal law of nature?

As geoscientists, we hold the knowledge (our scientific information, data and methods), which is not perfect, thus fallible, and always subject to possible changes and improvements by definition, as in any "truthful" science (Popper, 1959). If we have to do what is right, based on our scientific knowledge and a critical thinking, despite potentially bad consequences, then we have to be sure that our knowledge is advanced and scientifically updated, to be considered as true (that is, it possesses truly the qualities attributed to it).

- However, is our scientific knowledge such a universal truth?

If our knowledge is neither perfect nor absolute, nor a universal truth (and we know that):

- Can we answer in one or other direction to geoethical dilemmas (in good faith)?

If a geoscientist usually makes choices trying to look at the best consequences (or at least not the worst), sometimes bad consequences must be carefully evaluated and even accepted. Nevertheless:

- Who has to decide whether to accept bad consequences?

It is not always the duty of a geoscientist to take a decision among those options that appear in a given geoethical dilemma. For example, the final decision on the feasibility and implementation of an engineering geology intervention can depend not only on scientific and/or technological considerations, but also on political matters. However, geoscientists must not replace politicians, but "provide all the concrete and exhaustive elements to take a decision as sustainable as possible for that social and environmental system" (Peppoloni and Di Capua, 2017a). So, a geoscientist is ethically forced to properly inform, with no bias, those who are really in charge of the decision-making process. When the geoscientist also holds the decisionmaking duty, she/he has to look beyond geosciences and consider other reference systems (social, cultural, economic, etc.) in taking the decision

\section{THE NO ANSWER OPTION}

Modern philosophy has shown multiple ideas and reasoning about how to face ethical dilemmas. However, in the path to achieve a high ethical standard, it has been proposed that all individuals have to construct his/her own set of ethical values, targeting the highest level in the Kohlberg's stages of moral development (Kohlberg, 1982; Kohlberg et al., 1983). These stages (Table 1) are planes of moral adequacy conceived to explain the development of ethical reasoning. Kohlberg's stages of moral development constitute an adaptation of a psychological theory originally conceived by Jean Piaget (1896-1980) (Piaget, 1932).

Table 1: Kohlberg's planes of moral adequacy (adapted from Kohlberg, 1982)

\begin{tabular}{lcl}
\hline Level & Stage & Social driver \\
\hline $\begin{array}{l}\text { Pre-Conventional } \\
\text { (the morality of ac- } \\
\text { tions is judged by its } \\
\text { direct consequenc- } \\
\text { es) }\end{array}$ & 1 & $\begin{array}{l}\text { Obedience and } \\
\text { Punishment } \\
\text { (blind egoism) }\end{array}$ \\
\cline { 2 - 3 } $\begin{array}{l}\text { Conventional } \\
\text { (the morality of ac- }\end{array}$ & 3 & $\begin{array}{l}\text { Self-interest ori- } \\
\text { entation (instru- } \\
\text { mental egoism) }\end{array}$ \\
$\begin{array}{l}\text { tions is judged by } \\
\text { comparing them to } \\
\text { society's views and } \\
\text { expectations) }\end{array}$ & $\begin{array}{l}\text { Interpersonal } \\
\text { accord and con- } \\
\text { formity } \\
\text { (social relation- } \\
\text { ships) }\end{array}$ \\
\hline $\begin{array}{l}\text { Post-Conventional } \\
\text { (individual's moral- }\end{array}$ & 5 & $\begin{array}{l}\text { Law and order } \\
\text { morality } \\
\text { (social systems) }\end{array}$ \\
\cline { 2 - 3 } $\begin{array}{l}\text { ity may take prece- } \\
\text { dence over society's } \\
\text { morality: principles } \\
\text { include basic hu- } \\
\text { man rights as life, } \\
\text { liberty, and justice) }\end{array}$ & 6 & $\begin{array}{l}\text { Social Contract } \\
\text { orientation }\end{array}$ \\
\hline \begin{tabular}{l} 
Kohlberg's theory hold \\
\cline { 2 - 3 }
\end{tabular} & 6 & $\begin{array}{l}\text { Universal Ethi- } \\
\text { cal Principles } \\
\text { (Principled } \\
\text { Conscience: } \\
\text { mutual respect) }\end{array}$ \\
\hline
\end{tabular}

Kohlberg's theory holds that moral reasoning, the basis for ethical behavior, has six identifiable de- 
velopmental stages, each of them more adequate to respond to ethical dilemmas than the preceding stage. At stage 6, action is never a means to a goal, but it is an aim in itself; the individual acts because it is right and not for avoiding punishment, or for complying with social laws; he/she acts in the right way because this is mainly in his/her own interest. Although it is not easy to find individuals always acting accordingly with the highest ethical stage, which could be considered somehow utopian, we can consider this highest stage as a spur to push ourselves on that direction. Ideally, any individual must climb stages to the top, or at least try to climb, to elevate the ethical quality of his/her behavior. Most people rely on stage 5, assuming that following a given Social Contract (for example a deontological professional code of ethics/conduct) would be enough; others remain at stage 4 , following rules because they are in force, not due to deep conviction. The ultimate stage (stage 6) provides individuals with an impeccable ethical conduct, because of their deep conviction and consciousness that their ethical values are the right ones, even if they know those values cannot be considered universal laws.

Deontological theories may deny that consequences are of any concern, provided the intention was good. However, not all geoscientists will feel comfortable if their actions, although approved by deontological codes and in spite of their good intentions, result in harm to other people (society) or the environment. Thus, geoscientists cannot think that deontological codes are the last step for an ethical assurance where they can find all the necessary ways to face ethical dilemmas, whatever the consequences (Peppoloni and Di Capua, 2017b write about the '... tendency to confuse "the ethics of responsibility" with "the ethics embodied by the tool" ...'). They have to aspire to respond to ethical dilemmas starting from strong values and be conscious of the limits of their knowledge.

\section{CONCLUSION: THE DILEMMA OF DILEMMAS}

The main question we have to consider and answer is:

- Have ethical dilemmas a "right" solution?
According to present knowledge, they do not. As we have shown, a real ethical dilemma is a problem with no perfect solution in absolute terms. We can find only acceptable solutions concerning each specific context.

Thus, if real ethical dilemmas with a conflict between means and aims cannot simply be solved by a geoscientist:

- Where is his/her duty?

If there is no perfect solution to geoethical dilemmas, because the possibility of a conflict between what would be right and what is acceptable and wise to be done, and considering that in most cases a solution is expected from geoscientists:

- What has to be their professional attitude?

If we are facing a geoethical real dilemma, our first professional attitude must be accepting we cannot offer a unique right solution, but options and potential outcomes/scenarios. Our duty is to explain the choices and the consequences of each choice. We cannot fall on the mistake of considering our geoscience knowledge as a universal law, thinking we might solve any geoethical dilemma based on it and only it. But, we can suggest geoethical decisions by justifying them adequately from a scientific and technical point of view, and by clearly indicating pros and cons of the choice we are proposing, including a cost/benefit analysis also in societal and environmental terms, and including in our scientific analysis both probabilities and uncertainties. This approach is expected to lead to that point of equilibrium among positive and negative consequences (Peppoloni and Di Capua, 2017b).

However, geoscientists cannot be always able to propose solutions to real geoethical dilemmas. But, in this case:

- What are their professional duties? In which way can geoscientists best serve society?

Facing real geoethical dilemmas is mostly linked to our duties of omission (not proposing a given unique solution) than to select one because we really think, even in good faith, it is 
the lesser of two evils (the principle that when faced with selecting from two unethi$\mathrm{cal} /$ immoral options, the one which is least unethical/immoral should be chosen). We have to present, exclusively, technical-scientific data without influencing the choice of decisionmakers. It is not our duty, as geoscientists, to select among evils. We have to refrain from taking sides in such cases. In any case, our duty of informing remains, which means to clearly explain, to all the players, which are the evils and what consequences have to be expected whatever the decision taken would be.

Critical situations push us to offer solutions to geoethical dilemmas under great pressures and tight deadlines. This is the golden moment of our professional behaviour, when the highest ethical standards are requested and in which we must refrain from offering a scientific solution to the unsolvable. For example, during an intense seismic swarm in a high-risk area, prone to strong earthquakes, we could be asked to give our advice to evacuate or not a village for the possibility of a mainshock; this is a decision to be taken by decision-makers and not by geoscientists, since earthquakes are not currently predictable with any acceptable accuracy. When we are confronted with a geoethical dilemma, it could be good to think according to the Gödel theorem (Smith, 2007): the notion of truth in a system is not definable inside the same system. In the case of geosciences, this means that we have to accept the limitation of geosciences (our system) in offering true solutions to real geoethical dilemmas based solely on geoscientific knowledge. We have to let decision-makers take the final decision, based on principles other than geoscientific ones (from other systems). Our obligation, however, is to be clear on all the potential (geo)consequences for different options/scenarios, no more, no less.

It is time to better examine and rethink the challenge on how to approach geoethical dilemmas, creating consciousness about the values that should guide our professional duties, which do not finish because any deontological code says so. Moreover, geoscientists do not have only duties of informing, but in some cases also to refrain from taking a decision.

We must not answer what cannot be answered.

\section{REFERENCES}

Bobrowsky P., Cronin V.S., Di Capua G., Kieffer S.W., Peppoloni S. (2017). The Emerging Field of Geoethics. In: Scientific Integrity and Ethics with Applications to the Geosciences, edited by L.C. Gundersen. Special Publication American Geophysical Union, John Wiley and Sons, Inc.

Fieser J. (2017). "Ethics", The Internet Encyclopedia of Philosophy, ISSN 2161-0002, http:/ / www.iep.utm.edu/ethics/, accessed 18 October 2017.

Flew A. (1979). A Dictionary of Philosophy. London: Pan Books in association with The MacMillan Press. p. 134. ISBN 0-330-48730-2.

Grassian V. (1992). Moral Reasoning, Prentice Hall.

Kant I. (1764). Observations on the Feeling of the Beautiful and Sublime. Trans. John T. Goldthwait. University of California Press.

Kohlberg L. (1982). Moral development. In: Broughton J.M. \& Freeman-Moir D.J. (Eds.), The Cognitive Developmental Psychology of James Mark Baldwin: Current Theory and Research in Genetic Epistemology, Norwood, NJ: Ablex Publishing Corp.

Kohlberg L., Levine C., Hewer A. (1983). Moral stages: a current formulation and a response to critics. Basel, NY: Karger. ISBN: 3805537166.

Peppoloni S. and Di Capua G. (2017a). Ethics, pp. 1-5, doi: 10.1007/978-3-319-12127-7_115-1. In: Bobrowsky P.T. and Marker B. (eds.), Encyclopedia of Engineering Geology, Encyclopedia of Earth Sciences Series, Springer International Publishing, ISBN: 978-3-319-12127-7.

Peppoloni S. and Di Capua G. (2017b). Geoethics: ethical, social and cultural implications in geosciences. Annals of Geophysics, 60, Fast Track 7, doi: 10.4401/ag-7473.

Piaget J. (1932). The Moral Judgment of the Child. London: Kegan Paul, Trench, Trubner and Co., ISBN: 0029252407.

Popper K.R. (1959). The Logic of Scientific Discovery. 2002, Routledge, ISBN: 978-0-41527844-7.

Smith P. (2007). An Introduction to Gödel's Theorems. Cambridge University Press. 
Wall T.F. (2003). Thinking Critically About Moral Problems by. Belmont, CA: Wadsworth, ISBN: 9780534574239. 